\title{
Mulai Leave-datang Arrive-pulang Return. Working the Field Together: A Feminist Mother-Son Journey in Yogyakarta, Indonesia
}

\author{
Martina Padmanabhan
}

\section{Preceding the Beginning}

When did my journey to the field in Indonesia accompanied by a child really start? Did it begin when I found myself a single mother or with getting the research proposal granted in 2016? Or was it even earlier? When I applied for a professorial position with a focus on Southeast Asia, even if my roots rested in South India? Was the end of my marriage and the need to be accompanied by a child if I were to do field work a result of my earlier decision to move to Passau in the lower Bavarian hills? It is hard to disentangle the personal from the political in such events that led to me taking a year in Indonesia with Jacob, my then five-year old son.

M. Padmanabhan $(\bowtie)$

University of Passau, Passau, Germany

e-mail: Martina.Padmanabhan@uni-passau.de

(C) The Author(s) 2022

W. Harcourt et al. (eds.), Feminist Methodologies,

Gender, Development and Social Change, https://doi.org/10.1007/978-3-030-82654-3_6 
I remember sitting in a little café on the riverside, which the Dean (with whom I was preparing for the negotiations over tenure) had advised me to visit in order to enjoy a beautiful view of the bell tower of the baroque cathedral. Two years later I took refuge at the same spot to work on the final touches on a project on how to transform Indonesian farming into organic agriculture with an interdisciplinary consortium of anthropologists, sociologists and economists. Meanwhile my marriage had ended, and I was organising university life around my son Jacob, then still in kindergarten. Working late nights and in a constant hurry to ferry Jacob to and fro via bicycle marked my day, not to speak of mixed feelings of anger, sorrow and relief after a 19-year relationship with a now distant father, helicoptering in every second weekend.

In this state of mind, I polished the proposal prose. I threw in my long-standing interest and entanglement with organic farming, along with my newly established and rediscovered connections to Indonesia and my passion for fieldwork. I added one sentence. Just squeezing it to the bottom of the research design, I asked for the funding of a l-year guestprofessorship so that I could go to Yogyakarta myself while an interim takes over my tasks in Germany. This year off seemed to promise everything: warm feet, adventure, intellectual stimulus, freedom and more than once a place in a hammock. As Stolz et al. (2020) point out, the construction of the field starts with the preparation of a certain research topic. I envisaged the company of my son as a cheerful, curious, hand-holding little fellow.

\section{THEORY: ACCOMPANIED by Childiren in Field Research}

The impact of children on fieldwork and the challenges of being accompanied in the field have been discussed widely (Brown \& Dreby, 2013; Cupples \& Kindon, 2003; Flinn et al., 1998; Frohlick, 2002; Levey, 2009; Scheyvens, 2014; Sutton, 1998; Starrs et al., 2001). They consider the balance between work and family for field researchers and the need to think through logistics in a different light. The mutual influence of children on researching parents and vice versa is central to a change of positionality and destabilising of professional identities (Cornet \& Blumenfield, 2016). The research process might become more complex and multi-faceted due to parenting while in the field, but all research encounters are mediated by more experiences than just being in the field. 
With this paper I aim to reconstruct the effect of caring for a child during fieldwork, data collection and analysis and reflect on how I navigated bringing Jacob's presence into academic writing and reasoning.

The implications and challenges of accompanied fieldwork with a child is not very straightforward. Braukmann et al. (2020) direct their attention and efforts to analyse what it means to be a parent in the field. They specifically investigate, how caring for dependent young ones influences a researcher's positionality and the production of ethnographic knowledge. They explore the methodological, theoretical, and ethical dimensions of accompanied fieldwork. Interestingly enough their edited volume sprang out of informal hallway conversations and did not receive major funding, as parenting in academia mostly disappears into the invisible circumstance and thus forgoes epistemic gains such as creating other encounters, readings and affects. In this chapter, I would argue that reviewing such hidden care work with a feminist lens can enrich and demystify the concept of the "lonely genius" out in the field collecting data, and move towards a coproduction of knowledge (Millora et al., 2020). This applies not (only) in the sense of insights through the offspring themselves, but rather because of the magnifying/looking-glass effect their presence induces. Instead of revealing the "truth" we investigate, the staged character of the research enterprise becomes much more obvious by the ambivalent enacting of "family" and "academy". Thus, the notion of coproduction of knowledge encompasses not only lay experts, but everyday encounters.

Stolz et al. (2020) claim that such invisible family conditions are the stuff that rich and thick descriptions are made of. While studies of family lives tell us something about the engendered ways, stages and constellations of raising children, the (mis)fit of offspring into data collection further illuminates gendered positions within academia. Though literature provides insights into the field and its boundaries, accompanied fieldwork is rarely addressed as a methodological, counselling or institutional issue. Interestingly, multinational companies and development agencies run large human resource departments to organise and cushion intercultural translocations of accompanying families, while the equivalent family transitions for the purpose of research are less institutionalised or perceived in relation to a generalised notion of "rite de passage".

Just as academic procedures on the surface resemble each other at the German home university and at the hosting one in Indonesia, parenting seems a universal practice, but the field puts cherished cultural relativistic attitudes to test (Haug, 2020) and questions the idea of proper cultural 
(and parental) behaviour. Acknowledging the presence of a son in the field and the ways in which he is (in)directly linked to the making of the field turns the tale of "social isolation" into one of a "social experience". The solitary fieldworker and the single mother, the tension between sanitised data collection and the unspoken converge. There is the sense of a shared adventure, but also the risk involved when plunging into fieldwork with a minor is highlighted by uncertainty and more caution is felt when one considers which places to enter with a young dependant to trawl along.

Being accompanied by a child showcases in a straightforward way how multiple identities intersect in the process of field research (Cupples \& Kindon, 2003). The question arises of who are we in the eyes of whom? And it seems that the identities of mother, ex-wife, scholar and woman are much more interwoven (Hansen, 2016: 19) and less under control than we assume in routines of managing others impressions of self (or impression management). As Cupples and Kindon (2003: 223) highlight, "the instability of the self is brought home to us in an immediate way" when we take a child along, allowing faster, but possibly more painful access to the fragility of subjectivity. Bringing children to the field work challenges us to leave the restricted repertoire of the professional observer, when having to react and interact as the emotional, concerned and deeply involved participating parent. The "reposited other" as Gilmore (1998: 35 ) puts it can be observed differently when a child is around. Our role as parent, care-giver, discipliner, teacher and comforter sometimes obscures our professional/ researcher role. Impression management undergoes a severe destabilisation (Linnekin, 1998: 71), at the same time being with a child allows us to appear as this more human version of an academic. On the one hand there is "safety in motherhood" as a presumed universalism, but this is mediated by global inequalities and relations of power.

At close scrutiny, it matters how being accompanied by a boy reinforced my particular gendered, classed and ethnic subject positions in particular ways. It enabled my specific insights into the understanding of gender in contemporary urban Java, the concept of family and its centrality as the social centre, emphasised by large gatherings each Sunday. In this context single motherhood, though with a distant father in the background stands out oddly, mediated by the status of a bule white foreign academic. Ethnicity is blurred with class and erased by profession. All these reactions towards the mother and son pair provide a constant source of insights through the responses by him, by me and our community (Stolz et al., 2020: 23). 
What might turn into knowledge are in the very first place emotionally charged affects, which eventually provide epistemological insights (Studoka, 2019). But they come at a price. Accompanied fieldwork is "undoubtedly hard, frustrating and anxiety provoking" (Cupples \& Kindon, 2003: 217). More than the rather intellectual "labour of deriving a hypothesis" (Kunze \& Padmanabhan, 2014), affects heighten conflicts and provide insights disguised in pain. As no fieldwork is without affects, those caused by the intimate emotional relationship with a dependent minor pose a challenge in an academically induced framing exactly because the scholarly world derives from the tradition of unworldly, celibate and cerebral male monks (Lauggass, 2021). These tensions arise because of the ideas of the professional and the personal selves, between child and parent and are visible in the frictions that surrounds the field. As already indicated in the binary concepts of professional/private and grown-ups/minors, by ignoring the company of children we compartmentalise our research and ourselves. As Kleis (1987 in Shea 2016) argues, single parenting researchers have to adapt more than a lone researcher or a married pair as the needs are more diverse, but there are less hands to accommodate and ultimately cater to them. This multiplies the impact of cultural and environmental shock. The demands on the comforting and cushioning parent are much more felt and drastic.

My son caused me to be seen specifically as a mother and ex-wife, and not just as a visiting foreigner. Especially male researchers report how accompanying family made them more human to the community (Lozada \& Lozada, 2016: 116). Frohlick (2002) observes that women as professional researchers in the field continue to be more anomalous than footloose men because of wider continuing gendered conceptions of work and family. The critique of masculinist, disembodied models of fieldwork displays the double standards, where the double burden born by women professionals with family have to face disapproval, while the male version gains "street credibility" (Lozada \& Lozada, 2016: 116). Unsurprisingly, it is mostly women who write about accompanied fieldwork and the double challenge to be both a good professional social scientist and a good mother. In the background lurks the unspoken norm, that children should not be plucked from their safe home environment predictable routines and take them to unknown places away from their father (Tripp, 2002: 802).

The review of literature on doing fieldwork with a child by one's side reveals a number of feminist issues. Bringing the hidden care work in 
family life immersed in the research field to the limelight opens up the possibility of theorising this constellation as one among others in the field. Further, it helps to disenchant the aura of the lone male explorer to embrace an entangled coproduction of knowledge. The feminist lens rather emphasises the anyway staged character of the research enterprise and its simultaneous prosaicness. Nevertheless, there is no escape into the observer position, when participating as a concerned parent. Furthermore, the standing out of children in the field illustrates continuous gendered experiences within academia and as a deviation from the supposedly universal norm. The critique of masculinist, disembodied models of fieldwork displays the double standards, where women professionals face disapproval, while men go for glory. A feminist idea of fieldwork is not one despite of company, but because of being accompanied by children.

\section{Creating the Field Together}

Being accompanied impacts positionality and the power relations between the research and the researched. It reveals the field as something obviously constructed, as the connections to everyday life mean that we are always in the field, where professional and personal roles and relationships converge (Kartz, 1994). While Stolz et al. (2020: 23) counts the benefit of shared experience and memories, I was inspired to write a paper while navigating through the city together with Jacob on the scooter and his constant comments on the rural-urban landscape (Padmanabhan, 2020). I traced our journey in chronological and spatial order, starting from our house and ending at Jacob's school. At each of the places described along the way, I reflected on what they reveal about societal relations to nature in this rapidly growing metropolis. Only the constant transects due to school obligations allowed me for this series of observations. This example illustrated the politics of writing by deciding what belongs to the depiction of the field (Stolz et al., 2020: 22). Here the boundary work to maintain or rather construct the field becomes tangible.

The handsome (Indonesian looking) boy, who effortlessly blended into any Indonesian crowd phenotypically, was attracting some, but not too much attention. His entertaining qualities had a humanising effect on me, emphasising our vulnerability and dependency. As a daughter of an Indian father and a German mother, my skin colour is brown but I am too tall and thus stick out. Still my family heritage provided a surprising entry point into Yogyakarta. My father Padmanabhan-turned into family 
name under German family law in the 60s-shares his name with the oldest grammar school in our host city of Yogyakarta. ${ }^{l}$ What appears as a pleasant coincidence that opened doors within the academic strata of Yogyakarta, points to my positionality as a bicultural/intercultural person, embedded in century old privileges and to the syncretic nature of Javanese culture despite contemporary emphasis on an Islamic identity.

The personal and the professional self are hopelessly entangled and create intersecting identities. Simultaneously, we enact hybridity (Narayan, 1993) as those identities are mutually constitutive. We thus created this mother-and-son-package to be observed, related to and compared. As we behave differently when accompanied, interacting and sometimes breaking local norms of behaviour, we reveal ourselves, thus company makes differences more salient. The possible epistemological advantage of this often-shameful loss of control when impression management fails, is the chance to make us and the research situation more egalitarian, like emotional fits over mundane issues compelling me to let the mask of the self-controlled adult slip. Cupples and Kindon (2003: 212) state that the epistemological bearing of being accompanied by less self-controlled relatives lies precisely in this. The norm violating reaction to a child's transgression in return provokes in the very sense feedback and interaction, that allows insights into the rather controlled and hierarchical Javanese culture. If data is constructed through the research process itself, the multiple blurring between personal and professional identities affect the knowledge produced. But they also wonder whether the company of children prohibit necessary introspection for reflexivity? I would argue the contrary, but in unexpected ways. Inevitable homesickness, aggression and even boredom in the child (and the mother) as expressions of lost connectivity, frustration and loss of agency are common in cultural shock. These strong emotions tell us something about frames of meaning, emotional need and connectedness.

The embodiment of these feelings and reactions are of epistemological and theoretical importance, when we consider with Okely (1992: 2) that

\footnotetext{
${ }^{\mathrm{l}}$ Padmanabhan signifies in my case a South-Indian Brahmin pedigree, while the educational institution's name points to the Hindu and Buddhist heritage of/in Javanese culture. Founded in 1918 by the Dutch colonisers to educate the aristocratic Indigenous elite, it was renamed in 1942 under the Japanese occupation to Negeri Padmanaba (SMA_Negeri_3_Yogyakarta, 2020). The red lotus flower padma in Sanskrit, derived from Buddhist and Hindu traditions, represents the possibility of personal and spiritual development under any conditions.
} 
"the personal is the theoretical!" or with Moss (2001) that our autobiographical selves are a source of information. Especially forms of embodied knowledge are as telling for developing understanding as conventional data collection, when combining cultural analysis and interpretation with narrative details as in auto-ethnography (Heewon, 2008: 46). I would even go as far as to state a need to write through these 10 months of fieldwork and the preparatory time as well as the necessary recovery or reconciliation to arrive at my ability to analyse the core interest, the data concerned with organic farming itself. Writing through goes beyond the constant keeping of a diary and revealing WhatsApp notes throughout. Further it encapsulates the working through and reconstruction of the emotional and practical conditions of data creation. I dug out the circumstances of muddling through by analysing the inherent cognitive tensions with a feminist lens. What is constitutive for the resulting insights might resemble the data cleaning exercises required in surveys. While the latter terminates deviations, the feminist methodology exactly looks for these as a source of knowledge.

When recollecting my hopes, aspirations and expectations that motivated my pursuit of a long field stay, I cannot help but refer to Barack Obama's narration of his childhood in Indonesia (Obama, 1995). I read his memoirs in 2009 when I became the mother of Jacob and at that time did not imagine I would undertake field work in Southeast Asia. However, the story of in between, of biculturality and biracial origins in a third tropical country resonated with me and certain episodes stuck with me. In retrospect they inspired and shaped my idea of doing accompanied fieldwork in an indirect way. Revisiting our own experience, I recollect images from the autobiography that subconsciously turned into iconic emblems (like the plastic sandals see below), fuelling my determination. Only now, when rereading Obama's autobiography, it occurs to me, that his mother Ann Dunham engaged in anthropological field research close to Yogyakarta years later when her son was no longer living with her, but she was engaged in care work of his sister (Scott, 2012). Nevertheless, certain remarks acted as benchmarks and thus turn snapshots of Obama's childhood memories into a reoccurring theme. Interestingly, the anthropologists Dewey and Cooper (Dunham et al., 2009 ) as editors of Dunham's dissertation keep quiet about her fieldwork, obviously conducted while her daughter was around. Hefner (2009) remarks in passing that the reflexive turn had then not yet occurred as evident in the writing, while himself avoiding any methodological 
reassessment/reinterpretation. In fact, Dunham was a working and mostly a single mother bringing up two biracial children (Scott, 2012).

Feminist fieldwork accompanied by a child from the vantage point of creating the field together underlines the inherent politics of writing by deciding where the field boundary runs and whether it embraces the presence of a child. Cleansing the account of everyday facts upholds the myth of the detached observer and obscures intersectional settings. Children alter positionality and the power relations between the research and the researched. The transgressions of local norms by mother and child equally provoke reactions, irritate and at best entertain. The resulting feelings are of epistemological and theoretical importance. Through a feminist lens these cognitive tensions turn into an embodied source of knowledge.

\section{Mulai: LeAving BeHind}

Obama recounts in "the story of his family" 2 how his mother forced him to study English early in the morning before regular classes (Obama, 1995: 47), serving me as the ideal role model to reconcile the mother and the researcher. We will later find her dissertation on the shelves at our favourite loka-loka restaurant in walking distance up the street (Dunham et al., 2009). At that point I had long given up German home-tuitions as Jacob was single-mindedly embracing English with the desperate urge to communicate and make friends. In the end I did not advance in the accomplishment of Bahasa Indonesia as Jacob did in English. Only the working through our shared lifeworld in an allencompassing sense, demanded by the topic of inquiry at hand I realised our simultaneous being in the field in an almost constant way. In several ways we depended emotionally on speaking German among ourselves, while we both struggled with new, but different languages.

When it finally dawned on me that I would be granted a year of replacement as professor to allow me to go to Indonesia, a whole range of preparations had to be set in motion. On the one hand, an exploratory study with the team to officially start the research project at the hosting Atma Jaya University in Yogyakarta had to be prepared content wise along with the contracts. Staff recruitment in Germany and Indonesia brought a new group of people together; all concerned about the prospects of

\footnotetext{
${ }^{2}$ Subtitle of the German translation reads "Die Geschichte meiner Familie" (Obama, 2009).
} 
organic farming and the transformative pathways towards it. Similarly, I had to negotiate terms and conditions with the newly divorced father of Jacob for taking him along with me and placing $10,000 \mathrm{~km}$ instead of $700 \mathrm{~km}$ between us. What would the intervals of them seeing each other be, how to keep in touch?

During the exploratory study-presenting itself as a generic business trip, accommodated at the nearby "coffin" Suharto style hotel, full of high ranked military-we held official meetings. Jacob had already been present at the signing of the Memorandum of Understanding when we stayed for the first time for a month, and I took a language course and knitted together the necessary academic network. In between, I snuck away with an Indonesian colleague in order to have a look at the international school, recommended by the academic mother-cum-researcher network back in Germany. My heart jumped to see the recently founded Jogyakarta Community School with its green spacious lawns, beautiful classrooms full of artwork and a British curriculum. Jacob would have to learn English from scratch. On the way out I happened to inquire whether by chance anybody knew about vacant housing. And there we were: a teacher had just moved out (as we later learned because of the too close mosque and its very audible call to prayer in the early morning) and we drove by to have a look at the townhouse. There it transpired that my colleague assumed I would need to reside in a gated community. After visiting the two-storied, three-bedroom house with a spacious study, I instantly prepared a down payment with the nearby landlady on her beautiful wooden Javanese bed. The house, with access to internet, shopping and amenities of urban life, underscores the middleclass-ness of the whole research enterprise. The integration via a town house and the support by Indonesian colleagues reflects the class setting, along with the prospect of domestic help (see Padmanabhan, 2020).

The episode further shows, how the presence of a child shapes the considerations of a suitable living space. The closeness of the International School with a European curriculum to maintain educational continuity as well as family routines within our own walls were decisive (Cassell, 1987: 8). Stolz et al. (2020: 22) puts it as a promise of comfort and safety to keep a private "family" sphere apart from the field. This implied a certain way of isolation as well as socialisation and determined our integration into the Indonesian neighbourhood and the cosmopolitan school community. During our first joint trip we stayed at a guest house to test the waters, learn Bahasa and develop friendly working relations. This time, 
we came to establish ourselves for ten months, allowing Jacob to join a full year at school, taking into account the emotional and logistic cost of un- and resettling as advised by single mother researcher (Binder personal communication). A sabbatical plus teaching relief helped to synchronise our schedules and considered the needs of both of us involved. This meant cutting Jacob's summer holidays short though. This was the beginning of compromises and "satisficing" (Ward \& Wolf-Wendel, 2012: 43 in Blumenfield, 2016), looking beyond the overall satisfactory solution to cater for both needs of the professional and the personal, but rather for the viable. The tension from making decisions that are not optimal though perhaps good enough was a constant in this process, pointing to the lonely cowboy researcher as prototype in the background.

By shuttling in and out to check housing and schooling and indirectly the commute to the university, I realised I would have to get a motorbike myself, though I could not imagine how I could ever find my way through the small alleys and across the prohibitive highways. Nevertheless, my heart was full of hope and desire for adventure and getting to know the people of Java better. Obviously, though not officially in the limelight, fieldwork is no longer just about me as the researcher and the access to Indonesian academic institutions as host, employer of field staff and reference for important contacts and organisations, but about logistics that become far more complex as they have to consider the well-being of a child (Starrs et al., 2001).

Back home, we bought helmets and, at our grand farewell party, a concerned friend gifted me a voucher to use their scooter to practise driving a two-wheeler with a boy behind me as a pillion rider. Jacob and I mounted the orange two-wheeler, to find us within seconds of starting the engine on the gravelled street, not knowing what hurt or exactly happened-an immediate acceleration and there we laid. I had severely cut my left ankle above the bone. Jacob immediately proclaimed that we will not suffer any dreaded traffic accident in Indonesia as we already fulfilled our deed back home. And so it went. The open wound immobilised me and prohibited my attendance of a conference in Oxford and kept leaking and seeping during the long flight to Southeast Asia. Only the ready-made antibiotic cream available in Indonesia and the advice of a doctor-cum-co-mother from school made it heal.

My own cultural understanding of taking a child to a tropical country bears the imprint of a childhood dream long harboured. At the same time, it also presented itself as an escape route from routine. Simultaneously a 
research-stay in Indonesia proved to be an initiation period for claiming the Chair with a focus on Southeast Asia my own, a rite of passage in advanced age. Furthermore, the ability to take my child along reflects my financial and legal situation concerning shared custody. Last but not least, it represented a rite de passage affirming the new status from married to divorced woman. When the familiar world is exchanged for the field and left behind, almost all aspects from the choice of topic to places and logistics bear the imprint of a gendered if not intersectional consideration of the child's well-being and trades-off against the demands of work. Through a feminist perspective this complexity reveals the conditions for single academic mothers in the home and the host country.

\section{DAtang: Arriving IN Yogyakarta}

Obama recounts his arrival in warm and humid Indonesia and his encounters with animals as sensory overload and recalls thinking on his first night: "I could barely believe my good fortune" (1995: 35). He further describes slipping in the rain and happily sliding in the mud (Obama, 1995: 84). Jacob equally enjoyed working in permaculture garden as a way of place making along with the young men and roaming around in Bumi Langit, the organic estate run by the son of one of Ann Durnham's woman friends, visited by Barack Obama when returning to Indonesia. This juxtaposing of a strong picture that stayed in my mind and the happy hours of indulging in the new environment focuses on the heading into a shared adventure, at the expense of the possibility of physical and emotional threats (Stolz et al., 2020: 23).

There are positive and negative consequences of doing fieldwork with children. They provide emotional support to parents, reduce parents' loneliness, provide a way to maintain identity and provide a refuge while at the same time "drive parents crazy" and make them worry (Cornet \& Blumenfielf, 2016: 9). This is a truism and applies to parents back home as well. However, we could ask whether children perform an unwitting form of labour and have their rights violated, when acting as a research strategy and instrument for accessibility and a tool to humanise relationships. Making the children's contributions to research explicit is an important methodological and conceptual reframing (Blumenfield, 2016) and opens up a new dimension of research ethics. While the focus on power relations in data production is largely focused on those between 
researcher and researched, the potentially exploitative aspects of accompanying children are still to be captured in the dynamics and dilemmas. These special power relations within knowledge production touch upon emotional, bodily, and spiritual maintenance in place making.

\section{Emotional Maintenance}

The arrival to Yogyakarta was marked for Jacob by school attendance from almost the very first day onwards, with exiting encounters, followed by desperate claims to "I want to go back to Germany-immediately" while hiding behind mountains of pillows in his bed equipped with an mp3 player, featuring German radio dramas. Soon we were invited by Indonesian friends, acting as our adopted family to attend a huge wedding with 1000 guests in Surabaya. Here, Jacob intensively and silently observed the massive make-up application and my transformation through Javanese hairdos, thereby embracing cultural codes, thus oscillating between resistance and accommodation.

Shea (2016) describes the entering of the field with her daughter as no model rite of passage, but rather as loud and raw when she was struck with the sense that she was stuck in a strange place, unable to escape. The culture shock at young age is equally a culture shock and makes fieldwork with children "very messy indeed" (Shea, 2016: 50). Given the tremendous emotional work children have to go through themselves, it seems odd to read about their importance in place making. As Lozada and Lozada (2016) point out, children can provide not only a speedy introduction to neighbours in an unfamiliar field site, but also help develop future research relationships. They may further allay the anxieties of the researcher-parent by providing the pretext for a familiar routine (Blumenfield, 2016). It is comforting that exactly these cultural biases make us fully human (Glover, 2016) and enlarge the likeliness of insightful encounters. Children express their emotional needs. As adults we entertain different culturally determined strategies to cater for these needs, but the shared humanity is seen in the dependent children. The adult has voluntarily left the familiar herd to learn other ways of being. The child demonstrates the will to belong to a group and is less inhibited and self-censoring to express discomfort. A feminist claim is that of emotions as an entry point to emic understanding beyond the etic rational individualistic framework. 


\section{Bodily Maintenance}

Place making in a very fundamental sense is to familiarise ourselves and get accustomed with the chain of care, or rather the network of needs. We had to first explore the material and practical care. My language course notes focus on everything that enables us for shopping: gas cylinder, electricity, internet, food, water and vegetables, getting laundry done and buying fresh fruit juice. When the landlord helped us to get a new gas cylinder, he asked Jacob to accompany him in the car. Jacob enthusiastically reported back that at one point he was able to talk English: "I could talk just like magic". Via inquiries about stationary shops, postal services and home-made snacks sold on the street, we wove a fabric of social relations, which grounded us in routine, place and mutual recognition. Through the organisation of bodily needs, we connected to families and made friends, though the central vocabulary of the arrival period reads sulit difficult. The sounds of the neighbours also structured our day. The nearby Yoga school inserted me into a wild mix from hijabi housewives to beauty queen yogis, a seamless transition to spiritual maintenance.

Thus, the repetitive task of reproducing our working and learning capacity by eating and drinking, cooking and washing-the basic care for our bodies entangles us with the geography of our neighbourhood. These daily encounters create a fabric of the everyday out of which feminist insights are made when we take the whole of life worth considering as an expression of the larger picture of the economy and of provisioning.

\section{Spiritual Maintenance}

While the early morning sweeping of the street marked the start of the day in a mundane way of female routines, the call for prayer five times a day from a very close-by local mosque punctured the air with a constant reminder of the obvious spiritual dimensions of Java. Not only did the prayer times structure workshops and meetings, they also underlined the Indonesian concern with the religious dimension of human existence. Surrounded by fancy headscarf wearing students and the obvious pious fashion options, there was no escape. The religious dimension as perceived as a fundamental human trait is visible and audible in our surroundings. Recent Wahabitic Islamic traditions compete with old Javanese syncretic versions deeply influenced by Hindu and Buddhist heritage, 
while different Christian faiths are clearly visible in the academic landscape. The mosque next door allows us to observe the neighbour going for evening prayer. Jacob is invited by the landlord to join him and his sons and to learn about the religious and social centre, as a kindergarten is attached.

Being attached to a private catholic university, the presence of spirituality in higher education is visible in its representation (Chang \& Boyd, 2011 ) and among staff. Co-parents at Jacob's school teach at other Christian Universities and act as student ministers and invite us to Sunday services; our sons become best friends. Nevertheless, faith-based education institutions embrace other religions and enter into fruitful dialogues, crossing the narrow path of method and arts. At the former Jesuit seminar Sanata Dharma University I experience a deeply satisfying and very personal debate on transdisciplinary methods (Padmanabhan, 2018) motivated and framed by spiritual and social concerns. Just as affects and accompanying children as a human constant slowly enter the debate on knowledge production via feminist concerns for methodology, so does the spiritual aspects remain a well-guarded taboo as a source for insights in western academic thinking (Chang \& Boyd, 2011).

Much of the writing on accompanied fieldwork focuses on the advantages when settling in. A feminist research ethic will ask for the involuntary child labour kids are supposed to do, when turned into an instrument for accessibility and as the human factor-just as wives are often used/employed. Therefore, a feminist knowledge production is concerned with emotional, bodily, and spiritual maintenance in place making. The effect of multiple standards applied to working mothers on top of that in a new social environment can feel emotionally overpowering. The virtue of feminist methodology is not to swallow the overload, but to analyse and unpack these dissonances for knowledge production beyond the hegemonic. Similarly, bodily maintenance in everyday reproduction is the stuff feminist insights are made of, taking the mundane as an expression of the power structures in provisioning. Spiritual maintenance as well as childcare have remained understudied in field methodology. A feminist concern may bring both under-researched aspects into the heart of knowledge production. 


\section{Pulang: Returning and Intercultural Resonance}

Settling into university and school, becoming acquainted with colleagues and friends, we indulged in affective care and co-working as means to maintain our presence in Yogyakarta in the light of returning to Germany.

Indonesian staff in the project and the larger sociology department become important for the thin line between personal and academic resonance. Sharing long drives to interviews, hypothesising over interviews, planning workshops and strategies induces-like in every team lifecyclea sense of shared accomplishment and trust (Werner et al., 2013). An important part in this was played by two Indonesian researchers, who themselves had spent decisive years of their childhood abroad in Australia and Bangladesh, and thus were sensitised as persons able to consider insider and outsider perspectives. These deeply felt experiences as dependent children enabled them to act as translators of culture and as compassionate towards mother and child in a foreign academic setting.

One a different level, Indonesian colleagues entrenched in a Javanese identity attained a new quality beyond institutional counterparts when socialising with their families. Local staff, counterparts and their wives and children became an important social anchor, overriding the mere professional relation. They worked as a counter-medicine to the standalone project leader and solitary of a single mother and only child. This mingling told me indirectly, but also via shared interpretation about intercultural dissonances and thus ethics. The Javanese politeness and indirect way of expression sits in opposition to the comparatively loud and wild western children with their not strict enough parents.

At the beginning, the Indonesian Ersatzfamilie of the retired Bahasa Indonesia teacher as grandmother was central to making kin. They compensated for elder and experienced family members and active uncles, who were greatly missed and provided identity and belonging. With advancing time, those, who anchor the mother-son-duo as relational beings do change their WhatsApp connectivity with bodily presence. The visiting father/ex-husband bears witness to a streetwise boy, the brother/uncle and his wife explore neighbourhood food stalls and the grand/parents celebrate their grandsons ninth birthday, turning the locality through their visit into a shared place. 


\section{Expanding Mobility AND Trust}

Upward mobility in academia often means moving in the very sense; the willingness to go for fieldwork or research stays abroad implies relocation and social uprooting. While this holds true in the whole of academia, it is even more so seen as a given in development research. ${ }^{3}$ For many women at universities this poses the question of how to reconcile family obligations and career aspirations-or is it family aspirations and career obligations?- even more pronounced. When finally staying in Indonesia and leading a research team, the proposal for the EU funded Innovative Training Network WEGO was granted. The coordinator Wendy Harcourt invited me for a kick-off meeting in The Hague to celebrate International Women's day, get the consortium together and draft the list of applicants for $\mathrm{PhD}$ positions. While a video conference would have been an option, I decided to join the founding meeting for this international feminist political ecology network aiming at training the next generation of scholars. Meanwhile Jacob had developed a deep friendship with one of his classmates, who helped him to learn English, not feel lonely and play, as he expressed in an assignment on friendship in school. Based on his ability to form meaningful connections and socialise and my interest to widen the European academic circles, he stayed for a week with his friends' family. I took along a bamboo birdcage, painted red, and deposited it at the office of a puzzled Wendy. I preselected young researchers for fieldwork in Indonesia and India, started to get to know this wonderful crowd of feminist researcher activists and enjoyed the crisp air of The Hague. While this move speaks of trust in newly established bonds, it also reflects the logistical and financial ability to make this business trip happen. Back in Yogyakarta I could interview the Indonesian candidates.

Academic mobility appears as a fetish of speed and motion, disregarding the local, connected and long-term perspective. It seems paradoxical to sacrifice social relations for knowledge gains respectively to build social relations for the purpose of knowledge gains, posing relevant feminist questions towards an instrumental perspective on research encounters.

${ }^{3}$ Only Covid-19 has managed to question the mandatory hypermobility as accepted wisdom. 


\section{BIDDING FAREWELL}

With the school term coming to an end, I conducted the last interviews and we prepared for resettling by downsizing our household to luggage size. We conducted farewell visits, attended official closing dinners and threw a farewell party at Filosofi Kopi at the edge of a paddy field under large trees illuminated by lampoons. All the persons that had made Yogyakarta a place for us gathered to share food and coffee in the wonderful Javanese mix between formal speeches and informal chattering. The children roam around, exploring the terrain in the ultimate moment of most familiarity at the verge of leaving. In their chasing games, Jacob slips and falls into the rice field, showing up muddy, wet and happy to change into a dress to continue his chases. Soon we are seen off by Jacob's family friends as "his fifth best friend in a row", pointing to the transitory nature of expatriate communities and the challenge to transform newly formed relations.

The long-envisaged return meant entering the ongoing school and teaching term in Passau. While I met with the compassionate/understanding environment of the Chair focusing on Southeast Asia and a visit of the Indonesian Consul, Jacob was confronted with the hard task of resocialisation into a provincial school. Obama remembers the shift in value systems and categories when arriving in Hawaii vividly epitomised in the sandals that served him well in Jakarta, but were no longer good enough, thus experiencing a devaluation of his reference system. ${ }^{4}$ Though socially welcomed into the old and seemingly familiar class and neighbourhood, Jacob was not able to catch up with the German curriculum while his effective learning journey was totally ignored, if not denied. The multiple challenges of being unable to cope with the expectation in his mother tongue German in class and the non-existent mattering of his achievement made him fidgety. The reprimand of his Bavarian teacher "You are not any longer in Bali!" illustrates the humiliating mix of assuming unruly behaviour as the norm in the far away oriental place, while exchanging one Indonesian island for the other to underscore the irrelevance of it in an offhand way. This hard time coming back was totally unexpected for both of us, as home was supposed to be a comforting place (Christofi \& Thompson, 2007).

4 "The Indonesian sandals that had served me well in Jakarta were dowdy" (Obama, 1995: 60). 
The topic of home had gained a preserved, idealised quality as an outcome of homesickness. This static account did not allow us to comprehend and accommodate our inner change as well as the developments in our home base. While I had created a sketch book-cum-photo album during our first month long trip to Indonesia in 2015, only now I am able to produce a picture book for the sake of remembrance. I totally underestimated the emotional and intellectual energy necessary to return and reintegrate. Educators recognise that re-entry represents a crucial point, though it is often overlooked in programmes let alone by the lone researcher. Reflective practice might smoothen re-integration and navigate this often-overlooked transition. There is a need, but also an opportunity to integrate what has been learnt while away with previously held knowledge. A necessary methodological advance would be to institute a reflective practice. Blumenfield (2016: 78) suggests strategies for sharing the experience after leaving the fieldwork setting in a more conscious way. Having had family visiting and thus been able to reconnect to shared memories and create this continent spanning knowledge was an important part of calibrating the transition.

While working on the slight hubris of transforming Indonesian agriculture into organic, I was not able to envisage the necessary cushioning or actively shaping of transitioning back to the provincial town. Writing this chapter is still part of my returning process. As Blumenfield (2016: 78) puts it, including the messy, terrible moments of shared research as well as the joyful and fulfilling ones-in emotional and intellectual terms-helps to arrive as an honest assessment and simultaneously reassessment of the fieldwork process. From a feminist position, the awkward moments reveal not only analytic potential, but also the need to embrace the embodied experience of real women and real children.

Right now, I am full of warmth towards this energetic and enthusiastic young professor I was at that time, ready to conquer the world and make it "a world of my own" (Borzello 2000). Only through working through this embodied reality of my and Jacob's life of learning and researching Yogyakarta with a compassionate perspective I arrive at a point of coming to terms with this adventure. Seeing and analysing my data on organic farming is now possible in a light and relieved way, as I have revisited its coming about in a careful way, taking into account and actively embracing the care situation I was in, instead of harbouring a perspective highlighting the deficit. I am looking forward to turning the red bamboo bird cage, brought back to me by the Ph.D. students from The Hague to 
Passau, into the art installation of Yogyakarta I envisaged the moment I felt the urge to buy it.

Returning from doing fieldwork with a child and re-entering into cultural resonance from a feminist vantage point underscores the transitory nature of the whole endeavour. Just as the central research partners with childhood memories of moving between the emic and the etic acted as compassionate translators of culture, a care-full and embodied feminist research ethic requires entering into personal relations, as the children demonstrate. This leaves all of us vulnerable, highlighted in the awkwardness of homecoming. From a feminist position, a reflexive practice will bear analytic potential, when acknowledging the embodied experience of real women and real children.

\section{Conclusion: Coming to Terms Otherwise}

These interpretations of the cycle of departure-arrival-departurearrival reveal some emerging topics. The well-known stages of culture shock (Woesler, 2009) begin with honeymoon, the actual shock accompanied by doubt and uncertainty, followed by adaption and acceptance to be mirrored in the reverse culture shock upon return. However, only working through them while reflecting the solitary fieldworker and the single mother allows me to lay a finger on the tension between claims of sanitised data collection and the unspoken.

As Lozada and Lozada (2016: 116) state when recounting the work on accompanied fieldwork, "women's double-burden is alive and well" after 25 years of academic reflections on the implications of bringing children to the field. Though informed by sophisticated methodological and feminist thinking, deeply entrenched gendered expectations of parenthood and professionalism continue to inflect the experiences in the field and the knowledge produced from fieldwork. The child's presence contributes to a peculiar/idiosyncratic, not a distorted way of approaching organic and human transition in the (agricultural) field. By rather expanding the scope of the encounters co-producing knowledge, the objectives of these 10 months in Yogyakarta can be interpreted more expansively, as Blumenfield (2016) suggests. Binder (2020) highlights the emotional qualities of patience in her accompanying son, his ability to keep her firmly rooted in the reality of everyday life as place making and the co-production in sharing the adventure. 
Having arrived at this winter night in Covid-19 lockdown, I have moved from assessing the practical, ethical and emotional reality of fieldwork as complicated to rather being simply different by bringing a boy along. Embracing the everyday navigations as part and parcel of situated life and knowledge production promotes the relationship from one of deviation to that of a fuller feminist picture. The aim of the chapter was to deliberate over mistakes, detours and fear-only in retrospect to be revealed not as mishaps or fortunes, but rather as manifestations of necessary intellectual and emotional enquiry. Only by working through these enquiries could I actively bring Jacob's presence into academic writing and reasoning.

Concluding, I advocate the need for a mental reversal by conceptualising the researcher as an entangled, dependant and caring human, with emotional, intellectual and social abilities significant for knowledge production. Instead of posing the benchmarking hypothesis of the researcher as the independence claiming individual due to class, gender and other privileges, we might begin to ask precisely for the strings of networks attached to newly produced knowledge. Overcoming the guilt of not being a $24 \mathrm{~h} / 7 \mathrm{~d}$ researcher allows for channelling this energy into stimulating insights, thus being creative with family and research work.

Last but not least, what is feminist in doing fieldwork with a child at one's side? The minor keeps the feminist researcher grounded in everyday life as simultaneously place making and co-production of knowledge by sharing the adventure in an emotional, bodily and spiritual sense. Involuntary or not we are forced into reflexivity concerning identity, power relations and the creation of the field. Using these encounters headon is a timely addition to the methodological repertoire. Similarly, the co-production of knowledge through the conversations with the childfostered by the single parent, single child constellation-should move from the fringe into the limelight without overambitious expectations. Listening with care to affects and emotions, power relationships of ethicopolitical significance and practical material actions (Puig de la Bellacasa, 2017) in the everyday life with children in the field is a healing process to overcome inhibiting and forbidding binaries of either or. Through a tough thought process of reconciliation, we may turn the fiction of production and reproduction (Biesecker \& Hofmeister, 2010) into an enabling recognition of being in the world. 
Acknowledgements I gratefully acknowledge the most valuable comments of Wendy Harcourt, Christina Sathyamala, Ximena Argüello Calle, Constance Dupuis and Karijn van den Berg. I thank the organisers of the "Feminist Methodologies" workshop in August 2019 at Punti di Vista in Bolsena, Italy. Further I acknowledge the generous funding received funding from the European Union's Horizon 2020 research and innovation programme under the Marie Skłodowska-Curie grant agreement No 764908 WeGO-ITN on "Wellbeing, Ecology, Gender and cOmmunity-Innovation Training Network" and the German Federal Ministry for Research and Education Grant no 031B0233, Research for Sustainable Development, "IndORGANIC-The societal transformation of agriculture into bioeconomy-Turning Indonesia organic?". The patience, enthusiasm and emotional resilience of my son - disguised by an aliasand the whole team is highly appreciated. Last but not least I thank friends and family for accompanying me, to learn about the world and myself.

\section{REFERENCES}

Biesecker, A., \& Hofmeister, S. (2010). Focus: (Re) productivity: Sustainable relations both between society and nature and between the genders. Ecological Economics, 69(8), 1703-1711.

Binder, S. (2020). Women and crime in post-transitional South African crime fiction: A study of female victims, perpetrators and detectives. Brill.

Blumenfield, T. (2016). Blurred boundaries of learning and ethnography in an era of constant connectedness lessons from fieldwork with children in Southwest China. In C. Cornet \& T. Blumenfield (Eds.), Doing fieldwork in China...with kids! The dynamics of accompanied fieldwork in the People's Republic (pp. 69-85). NIAS Press.

Borzello, F. (2000). A world of our own: Woman as artists since the renaissance. Thames \& Hudson.

Braukmann, F. Haug, M., Metzmacher, K., \& Stolz, R. (Eds.). (2020). Being a parent in the field: Implications and challenges of accompanied fieldwork. transcript Verlag.

Brown, T. M., \& Dreby, J. (2013). Family and work in everyday ethnography. Temple University Press.

Cassell, J. (Ed.). (1987). Children in the field. Anthropological experiences. Philidelphia: Temple University Press.

Chang, H. (2008). Autoethnography as method. Left Coast Press.

Chang, H., \& Boyd, D. (Eds.). (2011). Spirituality in higher education: Autoethnographies. Routledge. 
Christofi, V., \& Thompson, C. L. (2007). You cannot go home again: A phenomenological investigation of returning to the sojourn country after studying abroad. Journal of Counselling \& Development, 85(1), 53-63.

Cornet, C., \& Blumenfield, T. (2016). Doing fieldwork in China...with kids! The dynamics of accompanied fieldwork in the People's Republic. NIAS Press.

Cupples, J., \& Kindon, S. (2003). Far from being "home alone": The dynamics of accompanied fieldwork. Singapore Journal of Tropical Geography, 24(2), 211-228.

Dunham, S. A., Dewey, A. G., \& Cooper, N. I. (2009). Surviving against the odds: Village Industry in Indonesia. Duke University Press.

Flinn, J., Marshall, L. B., \& Armstrong, J. (Eds.). (1998). Fieldwork and families. Constructing new models for ethnographic research. University Hawaii Press.

Frohlick, S. E. (2002). "You brought your baby to base camp?": Families and field sites. The Great Lakes Geographer, 9(1), 49-58.

Ghodsee, K. (2009). Single parenting in the field. Anthropology News, 50(7), $3-4$.

Gilmore, S. S. (1998). Both ways through the looking glass. The accompanied ethnographer as reposited other. In J. Flinn, L. B. Marshall, \& J. Armstrong (Eds.), Fieldwork and families. Constructing new models for ethnographic research (pp. 35-44). University Hawaii Press.

Glover, D. M. (2016). Viral signs. Confronting cultural relativism with children's health in the field. In C. Cornet \& T. Blumenfield (Eds.), Doing fieldwork in China...with kids! The dynamics of accompanied fieldwork in the People's Republic (pp. 85-99). NIAS Press.

Hansen, M. H. (2016). Between norms and science. What kids bring to the field. In C. Cornet \& T. Blumenfield (Eds.), Doing fieldwork in China...with kids! The dynamics of accompanied fieldwork in the People's Republic (pp. 19-39). NIAS Press.

Haug, M. (2020). Returning to the field as a mother. Reflections on closeness and difference in long-term fieldwork. In F. Braukmann, M. Haug, K. Metzmacher, \& R. Stolz (Eds.), Being a parent in the field implications and challenges of accompanied fieldwork (pp. 101-126). Bielefeld: Transcript.

Heewon, C. (2008). Autoethnography as method. Walnut Creek: West Coast Press.

Hefner, R. W. (2009). Afterword. Ann Dunham, Indonesia and anthropologyA generation on. In S. A. Dunham, A. G. Dewey, \& N. I. Cooper (Eds.), Surviving against the odds: Village industry in Indonesia (pp. 333-347). Duke University Press.

Kleis, G. W. (1987). City walls and campus groves in Northern Nigeria: A profile of parenting in the field. In B. Butler \& D. Turner (Eds.), Children and anthropological research (pp. 137-156). Plenum Press. 
Kunze, I., \& Padmanabhan, M. (2014). Discovering positionalities in the countryside: Methodological reflections on doing fieldwork in South India. Erdkunde, 68(4), 277-288.

Lauggass, M. (2021). Personal communication.

Levey, H. (2009). "Which one is yours?": Children and ethnography. Qualitative Sociology, 32(3), 311-331.

Linnekin, J. (1998). Family and other uncontrollables. Impression management in accompanied fieldwork. In J. Flinn, L. B. Marshall, \& J. Armstrong (Eds.), Fieldwork and families. Fieldwork and families. Constructing new models for ethnographic research (pp. 71-83). University Hawaii Press.

Lozada, E. P., Jr., \& Lozada, E. P., III. (2016). Opening the door (kaimen). In C. Cornet \& T. Blumenfield (Eds.), Doing fieldwork in China...with kids! The dynamics of accompanied fieldwork in the People's Republic (pp. 100-119). NIAS Press.

Millora, C., Still, E., \& Maimunah, S. (2020). Reflecting on the ethics of PhD research in the Global south: Reciprocity, reflexivity and situatedness. Acta Academica: Critical views on society, culture and politics, 52(1), 10-30.

Moss, P. (Ed). (2001). Placing autobiography in Geography. Syracuse, NY: Syracuse University Press.

Narayan, K. (1993). How native is a 'native' anthropologist? American Anthropologist, 95(3), 671-686.

Obama, B. (1995). Dreams from my father. A story of race and inheritance. Canongate.

Obama, B. (2009). Ein amerikanischer Traum. Die Geschichte meiner Familie. Deutscher Taschenbuch Verlag.

Okely, J. (1992). Anthropology and autobiography: Participatory experience and embodied knowledge. In J. Okely \& H. Callaway (Eds.), Anthropology and autobiography: ASA Monographs 29 (pp. 1-28). Routledge.

Padmanabhan, M. (2018). Transdisciplinary research and sustainability. Collaboration, innovation and transformation. Routledge.

Padmanabhan, M. (2020). Navigating the urban rural frontier in Yogyakarta. In S. Kurfürst \& S. Wehner (Eds.), Southeast Asian transformations: Urban and rural developments in the 21st century (pp. 9-24). Transcript Verlag.

Puig de la Bellacasa, M. (2017). Matters of care: Speculative ethics in more than human worlds. University of Minnesota Press.

Scheyvens, R. (Ed.). (2014). Development fieldwork: A practical guide. Sage Publications.

Scott, J. (2012). A singular woman. The untold story of Barack Obama's mother. Riverhead.

Shea, J. L. (2016). Clean your plate and don't be polite: An American mother's education in early childhood parenting and family life in Shanghai, China. In C. Cornet \& T. Blumenfield (Eds.), Doing fieldwork in China... with kids! The 
dynamics of accompanied fieldwork in the People's Republic (pp. 40-68). NIAS Press.

SMA_Negeri_3_Yogyakarta. (2020). Padmanaba: SMA Negeri 3 Yogyakarta "School of Leadership". Retrieved February 3, 2021, from https://sma3jo gja.sch.id/.

Starrs, P. F., Starrs, C., Starrs, G. I., \& Huntsinger, L. (2001). Fieldwork ... with family. Geographical Review, 91(1-2), 74-87.

Stodulka, T., Dinkelaker, S., \& Thajib, F. (Eds.). (2019). Affective dimensions of fieldwork and ethnography. Springer.

Stolz, R., Metzmacher, K., Haug, M., \& Braukmann, F. (2020). On being a parent in the field. Practical, epistemological, methodological and ethical implications of accompanied fieldwork. In F. Braukmann, M. Haug, K. Metzmacher, \& R. Stolz (Eds.), Being a parent in the field: Implications and challenges of accompanied fieldwork (pp. 9-38). Transcript Verlag.

Sutton, D. (1998). "He's too cold!" Children and the limits of culture on a Greek Island. Anthropology and Humanism, 23(2), 127-138.

Tripp, A. M. (2002). Combining intercontinental parenting and research: Dilemmas and strategies for women. Signs: Journal of Woman in Culture and Society, 27(3), 793-811.

Ward, K., \& Wolf-Wendel, L. (2012). Academic motherhood: How faculty manage work and family. New Brunswick, NJ: Rutgers University.

Werner, S., Padmanabhan, M., \& Christinck, A. (2013). Adding value to research through partnerships: Interdisciplinary and intercultural diversity in agrobiodiversity research. In A. Christinck \& M. Padmanabhan (Eds.), Cultivate diversity! A handbook on transdisciplinary approaches to agrobiodiversity research (pp. 93-114). Margraf Publishers.

Woesler, M. (2009). A new model of cross-cultural communication: Critically reviewing, combining and further developing the basic models of Permutter. Yoshikawa, Hall, Hofstede, Thomas, Hallpike, and the social constructivism. European University Press. 
Open Access This chapter is distributed under the terms of the Creative Commons Attribution 4.0 International License (http://creativecommons.org/ licenses/by/4.0/), which permits use, duplication, adaptation, distribution and reproduction in any medium or format, as long as you give appropriate credit to the original author(s) and the source, a link is provided to the Creative Commons license and any changes made are indicated.

The images or other third party material in this chapter are included in the work's Creative Commons license, unless indicated otherwise in the credit line; if such material is not included in the work's Creative Commons license and the respective action is not permitted by statutory regulation, users will need to obtain permission from the license holder to duplicate, adapt or reproduce the material.

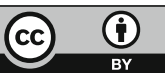

